\title{
Os são-simonianos e a colonização da Argélia ${ }^{1}$
}

\author{
SMAÏL HADJ ALI
}

A POLÍTICA COLONIAL do Ocidente, graças à atualidade (Iraque) ou à história (Argélia) é novamente, explicita ou implicitamente, objeto de debates, com o retorno, tanto no primeiro caso quanto no segundo, da tese da "boa colonização". O texto que segue recorda a multiforme e impressionante contribuição dos são-simonianos ${ }^{2}$ na elaboração do mito da "boa colonização", filha própria da "associação universal" dos povos, e interroga-se em filigrana sobre a atualidade e a influência, direta ou indireta, da ideologia são-simoniana hoje.

O que nós nomeamos são-simonismo colonial, da mesma forma que existiu o "socialismo colonial" ou o oxímoro "colonização de progresso", identifica-se, ainda hoje, com a idéia, transformada em paradigma, da "boa colonização". Estudos, ensaios eruditos, livros de recordações e reedições de textos comentados sobre a colonização da Argélia concordam em reproduzir, nestes tempos de amnésia generalizada, a idéia segundo a qual houve uma "boa colonização" ou, ainda mais sutilmente, que, ao lado de uma colonização lamentável, existiu uma boa.

Em maio de 2003 essa tese materializou-se com a apresentação de um projeto de lei " "visando ao reconhecimento da obra positiva de nossos concidadãos que viveram na Argélia...".

Um pouco antes, um político, ministro várias vezes, escrevia: 4 "Não podemos julgar o período colonial [...] esquecendo o legado de bens, entre os quais em primeiro lugar a escola, que [a França] transmitiu aos povos colonizados, com os valores da República, as armas intelectuais para sua própria libertação...”. E ainda: "Podemos sustentar sem paradoxo que foi a França que permitiu à Argélia ser a grande nação que ela se tornou”. Essas posições lembram aquelas dos são-simonianos, mas também outras correntes de idéias que, para além de suas clivagens, diminuindo ou ignorando os crimes da guerra de conquista e a opressão colonial, celebraram "a dinâmica da educação" e a "civilização", como Victor Hugo: "É a civilização que marcha contra a barbárie. É um povo esclarecido que vai ao encontro de um povo nas trevas. Nós somos os gregos do mundo; cabenos iluminar o mundo".

Percorrendo alguns estudos eruditos consagrados aos são-simonianos, podemos ler que: ${ }^{5}$ 
Enfantin ${ }^{6}$ quanto a ele, verá na colonização da Argélia uma chance histórica para acelerar a fusão das civilizações européia e oriental. É lamentável, sob vários pontos de vista, que seu desejo de ver a conquista argelina produzir "uma associação com o vencido que fosse para este, em definitivo, tão vantajosa quanto o era para o vencedor", assim como seus conselhos relativos ao respeito devido às populações subjugadas e às suas instituições, não tenham sido mais ouvidos.

Um outro nos diz que: “Os são-simonianos, em sua grande maioria, apóiam a colonização, mas de uma forma suave, que evitasse um choque frontal com as populações árabes".

Um terceiro, finalmente, apresentando a obra de um são-simoniano partidário de uma colonização "humanista" e que, apesar disso, "nunca perde de vista os interesses da França", avalia que "a administração militar" soube tomar "medidas sábias e úteis" para os colonizados e que esses "realizaram progressos consideráveis".

A colonização, em sua versão são-simoniana, não é mais um sistema de opressão, pois ela soube levar, ou poderia ter levado, a "doçura" no contato com o colonizado e "o respeito" para com ele. Finalmente, essas posições banalizam um sistema, o imperialismo colonial, o qual, para ficar apenas no nível do seu "porão", foi um método de acumulação primitiva apoiado na força bruta.

\section{Sobre a periodização}

Antes de abordar o papel e a ação dos são-simonianos, ou seja, essa capacidade de colocar em redes a economia, o comércio, a ciência, as comunicações, a guerra e a "submissão" a serviço da colonização, detenhamo-nos na escolha da periodização.

Cristalizando várias fases do empreendimento colonial, ela é também o momento em que são forjadas a doutrina e a engenharia colonial, nutridas por ideologias diversas e adversas.

Se o ano de 1830 ainda não é significativo da ação são-simoniana, ele é indicador da participação zelosa de oficiais politécnicos, como Lamoricière, cuja fulgurante ascensão o conduzirá ao posto de ministro da Guerra no governo de Cavaignac, general iniciador da prática do enfumaçamento ${ }^{7}$ dos argelinos.

Mas o interesse dos são-simonianos pela Argélia não se reduz a uma participação de oficiais vindos para lavar a afronta de um "golpe enxota-moscas". ${ }^{8}$

Já em novembro de 1831, o jornal são-simoniano Le Globe afirma que a colonização iria proporcionar "aos povos atrasados os sentimentos religiosos, isto é, associação, luzes e abundância". Em 1833, Emile Pereire ${ }^{9}$ propõe incorporar a Argélia à França e dividi-la em três departamentos. Essa proposta, feita após três anos de guerra, explica a escolha do ano de 1848 como data limite de nosso recorte neste artigo. É de fato em novembro de 1848 que a proposta de Pereire é oficializada pela segunda República. Essa decisão ratificava o decreto de março de 1848 tomado por um governo formado por personalidades que invocavam democracia e humanismo, mas também por são-simonianos de "esquerda” como Lazare H. Carnot, ministro da Educação, ou Jean Reynaud. 
Ao mesmo tempo que assinala o triunfo do exército colonial, o ano de 1848 pode ser considerado como a síntese de uma época que, da Monarquia de Julho à proclamação da Segunda República, afirma um amplo consenso das elites francesas quanto à colonização, independentemente de filiações ideológicas. ${ }^{10}$

\section{Os pioneiros}

Os são-simonianos, particularmente os enfantinistas, mantiveram uma relação forte com a Argélia, seja na primeira expedição francesa de conquista seja, como mais tarde, quando da guerra de conquista ou ainda durante o processo colonial; em alguns casos, como o de Lamoricière, tal relação existiu nesses três momentos. Eles ofereceram à empreitada colonial suas idéias, seus projetos, sua ciência, seu savoir-faire militar. Sem exagero, pode-se dizer que a Argélia foi uma "carreira" para eles. Esse termo, emprestado de Disraeli, qualificava a ação dos britânicos - cientistas, militares, políticos - que tinham partido em conquista de um Oriente que a eles se submeterá e que eles fabricarão a partir de doutrinas fundadas na superioridade européia e na idéia de um árabe-muçulmano percebido "como uma espécie de abstração ideal, imutável” (Saïd, 1978, p.20).

"Carreira", mas também laboratório onde são concebidas teorias e técnicas de subjugação. Os primeiros testemunhos de são-simonianos provêm de Bigot e Lamoricière, dois oficiais formados pela École Polytechnique.

É por intermédio do primeiro, amigo de Enfantin e companheiro de promoção de M. Chevalier, que as idéias de "Família" a morte de Bigot, Lamoricière dirá: "Nós tínhamos sido durante muito tempo os únicos são-simonianos do Exército da África [...] nós tínhamos conseguido atrair em nossa direção muitos de nossos camaradas".

Lamoricière simbolizará o ideal são-simoniano por meio do desenvolvimento de uma rede da guerra moderna, da qual ele dirá que ela "é uma obra de apostolado junto a pessoas que não entenderiam por muito tempo argumentos que não fossem apoiados pela ação das baionetas. Eu vejo a conquista como um poderoso meio de importação de idéias".

Muito afetado pela cisão da "Família", ele declara: "Eu desejaria muito saber $[\ldots]$ qual a causa desta infeliz separação".

Se o cisma não tem conseqüência sobre os enfantinistas da metrópole quanto à sua visão do Oriente, que eles continuarão a pensar em termos de "associação universal" - assim como os partidários de Bazard -, o mesmo não ocorre para os de Argel, que "não procuram de modo algum disseminar sua religião nos meios árabes" (Lacheraf, 1961).

\section{Exploração e produção científica}

Esses também não eram os objetivos das autoridades ocupantes e de suas promessas de "educação" e "benefícios da ciência".

$\mathrm{Na}$ falta de disseminar a filosofia das "Luzes", a França enceta, paralelamente a uma guerra devastadora, ações de descoberta conduzidas por oficiais peritos. 
Desde 1833, a necessidade de conhecer melhor o país torna-se negócio de Estado, como atesta o ministro da Guerra solicitando às instituições científicas que preparem a exploração da Argélia e produzam mapas, que são o "instrumento mais útil para [...] a colonização da África" (Dondin-Payre, 1995, p.22). A partir disso nascerá, em 1839, a Comissão de exploração científica da Argélia, da qual serão membros Enfantin, que será seu relator para a parte histórica, e o capitão Carette. A comissão será integrada também por Ismaïl Urbain, na qualidade de intérprete, pelo doutor Warnier, autor de uma lei fundiária destruidora, além de outros simpatizantes. Às primeiras descobertas sucede um vasto empreendimento de exploração científica de uma sociedade transformada, a despeito de si, em objeto de estudos que mobilizam todas as ciências e disciplinas disponíveis: geografia, etnografia, antigüidades, geologia, agronomia, química etc.

Os objetivos da Comissão não se limitam à acumulação de informações científicas. Explorar e produzir cientificamente a Argélia é também assentar a colonização.

Auxiliar da dominação, a ciência deve produzir o nascimento do país conquistado, um nascimento fundado sobre sua retificação histórica e identitária. Esse empreendimento dá ensejo a uma conivência entre cientistas, políticos e militares.

Essa não se limita, entretanto, à Comissão, e é repartida pelas "vanguardas viçosas e alegres da colonização", para retomar uma bela fórmula de Jacques Berque.

É ligada a essas linhas de conduta e a esse contexto que a contribuição dos são-simonianos deve ser apreendida.

Qual foi exatamente o papel deles? Como se associaram a essa política da ciência? É o que veremos abordando o papel de Enfantin (1843) após ter recordado brevemente o de Carette, esse "colega e amigo", segundo Enfantin, cuja amizade foi consolidada no seio do jornal L' Algérie. Não trataremos do papel de Urbain, cuja ação confundiu-se sobretudo com a política "do Reino Árabe", ainda que ele tenha produzido notas e relatórios - dos quais Enfantin irá servirse - impregnados de uma "filosofia" da autocolonização, baseada na participação dos “indígenas ${ }^{12}$ da Argélia no trabalho de colonização", isto é, em sua própria alienação. Para isso, leiamos um extrato de uma carta endereçada ao ministro da Guerra em 1837 para solicitar um cargo de intérprete, que ele exercerá junto a Bugeaud num primeiro momento:

No momento em que o governo se prepara para a expedição de Constantine, venho solicitar-lhe aceitar meus serviços confiando-me o emprego de secretário intérprete adido à expedição [...] Após minha chegada ao Egito, para melhor conquistar a confiança dos árabes e para que nenhum dos recônditos secretos de seu caráter permanecesse oculto de mim, tive a coragem de adotar sua religião e de proceder à minha própria circuncisão. Cultivei a esperança de que esse ato [...] tornar-me-ia um dia útil à França em suas possessões africanas... 
Essas palavras não denotam, além da astúcia, um "espírito espontâneo de dominação”, já presente em Tocqueville ou Lamartine?

\section{Uma contribuição multiforme}

A contribuição dos civis são-simonianos para a política da ciência foi inseparável do quadro estatal que Enfantin coloca de imediato: "O espírito de associação, e a maior de todas as associações, o governo, pode empreender com sincronia, com ordem, uma colonização científica".

Essa vontade de posicionar assim sua contribuição - a Comissão depende do Exército, seu chefe é um coronel - não os impede de desenvolver uma certa autonomia de ação, de trabalhar a favor de suas idéias e projetos e de esforçar-se em fazer que eles fossem compartilhados pela administração colonial, por personalidades influentes no seio do poder de Estado, industriais e homens de negócios. Essa autonomia irá afirmando-se e, em 1845, Enfantin pode declarar: "Jamais permitiremos a ninguém dirigir os negócios da Argélia se não estiver de acordo conosco". Isso posto, a relação com o Estado nunca é perdida de vista.

Essa contribuição, no fundo, participa do assentamento de uma rede colonial em conformidade com o desenvolvimento, as urgências e as necessidades da economia e do Estado francês, o que já exprimiam, aliás, logo após a Revolução de julho de 1830, as palavras do marechal Gérard ao general Clauzel: a Argélia deve tornar-se "um vasto desaguadouro para nossa população supérflua e para o escoamento dos produtos de nossas manufaturas".

\section{Técnicos e teóricos da colonização}

Se a técnica colonial identifica-se com a ação de estabelecer regras e planos e de posicionar homens, então podemos considerar que certos são-simonianos foram técnicos da colonização, inspirando, influenciando ou antecipando as decisões e as escolhas dos responsáveis militares, civis e dos empreendedores. A isso acrescenta-se sua capacidade de conceber, de defender teorias, modelos políticos e econômicos e de propor uma visão de mundo fundada sobre um sistema de idéias voltado para os interesses da formação econômica e social francesa. A esse respeito, Enfantin torna-se um teórico e técnico da colonização no plano econômico, mas também - após outros, é verdade - da colonização de povoamento, "que deve ser européia, cristã e não exclusivamente francesa, ainda que feita sob a dominação francesa".

Entre esses técnicos e teóricos, vejamos o caso do capitão Carette. Desde sua chegada, em 1835, ele se coloca totalmente a serviço da colonização e recenseia as possibilidades de exploração do território e das riquezas materiais. Ávido por conhecimentos, ele oferece perspectivas práticas à ciência, ao exército e à indústria franceses. Seus trabalhos, citados por Enfantin, tratam das vias de comércio, das tribos e apóiam-se sobre mapas por ele próprio elaborados. A Cabilia (Carette, 1848) e o Saara ocupam-no particularmente. Etnografando os cabilas, esses "aborígines" que falam uma "língua pobre", ele procede a um "inventário 
de questões que se ligam [...] aos interesses franceses", isto é, à "delimitação, divisão, configuração e aspecto do solo", mas também aos "hábitos de trabalho e de troca", assim como ao "estado político ou às relações entre as tribos". Esse inventário é essencial, pois "a dominação da Cabilia é um negócio industrial”. Inspirando-se em M. Chevalier, ele se interessa pelo Saara e declara que "a dominação do Saara é um negócio comercial". A junção da Argélia com a África deve passar pela conquista e pelo controle das antigas vias de comunicação e pela criação de novas. Para esse projeto ele deseja recrutar informantes "indígenas", no que Enfantin já tinha cogitado, com seus "árabes" “caixeiros-viajantes da ciência e do comércio". Um livro sobre esse tema será publicado em 1844, intitulado Do comércio da Argélia com a África central e os Estados barbarescos. Carette será nomeado prefeito de Constantine em fevereiro de 1848. Passemos a Enfantin.

Nomeado por um decreto real de 18 de agosto de 1839, por intervenção de um tio, o general Saint-Cyr Nugues, Enfantin desembarca em Argel em dezembro de 1839. Oficialmente ele deve ocupar-se "de trabalhos relativos à etnografia, história, costumes e instituições". Essa nomeação no seio de uma instituição acadêmica é indicativa de seu afastamento da herança intelectual de Saint-Simon. ${ }^{13}$

Acolhido como o messias pela "Família" de Argel, ele zomba do etnógrafo em que se "transformou": "Assisti ontem à noite a uma dança de negros [...] o que não é atraente nem pela música, nem pelos saltos, nem pelo cheiro [...] $\mathrm{E}$ pensar que caberá a mim relatar como é que essas meretrizes rebolam".

Para ver a guerra ele obtém, por "favor especial” do general Galbois, cujo intérprete é Urbain, a autorização de acompanhar uma expedição de "pacificação". Durante quinze dias ele segue uma coluna, assistindo às suas operações e às exações por ela cometidas.

\section{Construir uma "rede colonial"}

Ao dar conta apenas de algumas das posições de Enfantin, estamos conscientes dos limites deste trabalho. Com efeito, uma obra só recebe seu verdadeiro sentido se for integrada a uma parte substancial de uma vida, algo a que não podemos pretender no âmbito deste artigo. Uma vez estabelecidos tais limites, as idéias desenvolvidas por Enfantin em seu livro não podem ser consideradas exclusivamente como expressão de seu ponto de vista. Elas exprimem, para além de sua visão pessoal, também as idéias de um grupo cujo objetivo traçado é "a dominação dos indígenas". O discurso de Enfantin exprime, portanto, uma visão de mundo que, uma vez conceptualizada, permite apreender, para além do papel e da ação dos indivíduos, a relação dialética que funda suas práticas e seu sistema de idéias.

Por sua vez, o são-simonismo colonial deve ser estudado em sua dimensão ideológica se desejarmos apreender, a seu respeito, "a disciplina extremamente sistemática que permitu à cultura européia gerar - e mesmo produzir - o Oriente do ponto de vista político, sociológico, militar, científico e imaginário, durante o período que sucedeu ao século filosofia das Luzes". 


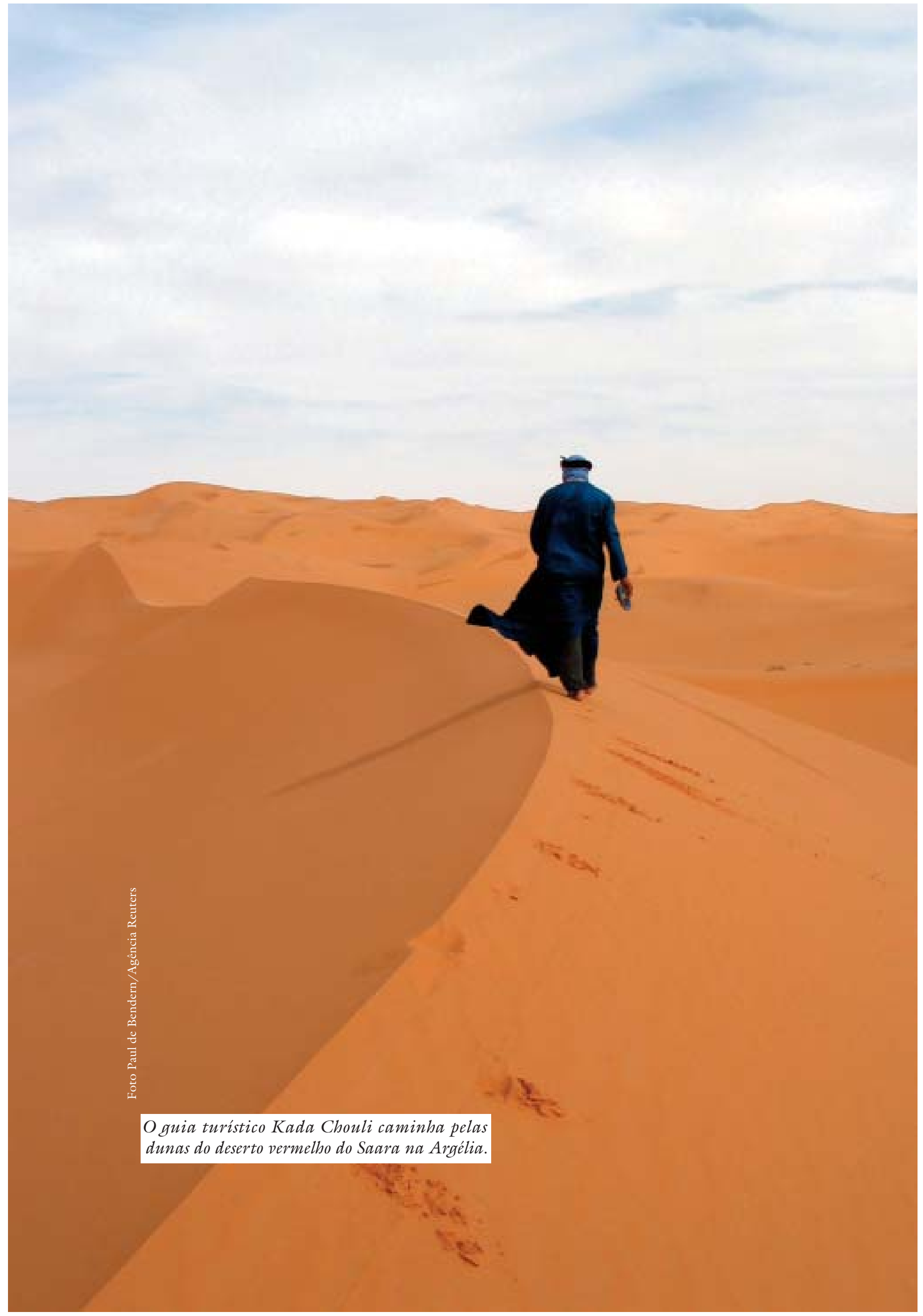


Ideologicamente, o livro de Enfantin é um discurso sobre a inferioridade dos outros, e é a esse título "um conjunto de posições, de atitudes, de idéias compartilhadas" por uma "coletividade em um momento de sua história". Essa totalidade, a ideologia, age como um "torniquete que permite aos discursos e aos atos fortalecerem-se mutuamente". O estudo da produção desse discurso permite rastrear o parentesco ideológico entre textos que a forma separa.

Nesse sentido, os registros desenvolvidos - científicos, econômicos, políticos - não fogem a essa regra, e é efetivamente o paradigma da inferioridade que estrutura todo esse discurso.

Lugar de uma produção de dados com pretensão científica, ele é ao mesmo tempo um condensado raro de estereótipos, de idéias preconcebidas sobre a história, a cultura, o fundo identitário árabe-bérbere e a civilização árabe-muçulmana. Ele participa assim plenamente dos preconceitos e dos racismos de sua época, sejam quais forem em outros aspectos os impulsos generosos do discurso sãosimoniano sobre o Oriente, ou a vestimenta humanista de um discurso retificador e pejorativo sobre a história multimilenar da Argélia e da civilização árabe e muçulmana.

Retomando a propaganda oficial colonial, ele legitima o "direito de conquista" e "a posse da Argélia", "legítima e irrevogável”. Essa legitimidade, proclamada em nome de uma guerra preventiva, apóia-se na necessidade de livrar "os mares da pirataria argelina", quando na verdade, em 1830, ela não existe mais em conseqüência do declínio do mundo otomano e de sua derrota na batalha de Navarino (1827).

\section{Racionalizar, organizar a colonização}

Lembrando que aos "esforços de ocupação" era preciso "reunir esforços de colonização" e "acompanhar nossos atos inevitáveis de destruição de potentes tentativas de produção", ele deseja compartilhar com "nosso governo da Argélia" a seguinte questão: "Em que sentido é preciso modificar as instituições, os costumes e práticas dos INDÍGENAS?" e "elevá-los ao sentimento de civilização, de associação, do qual nós fomos sempre os representantes mais generosos...". Mas o que significa uma tal "associação", atrelada a uma "rede de submissão", para retomar seus próprios termos?

"Rede organizadora", a "rede de submissão" deve "favorecer a dissolução das grandes tribos", "constituir [...] vigorosamente os aduares" e "destruir as estruturas sociais existentes". Os "indígenas" devem ser organizados nessas pequenas estruturas para facilitar sua integração na "rede de submissão". Isso é "civilizar a Argélia, e nós temos essa pretensão". Assinalemos que essas propostas serão sistematizadas por um decreto-lei senatorial em 1863, que liquidará a propriedade indivisa e esfomeará as populações.

Sobre as formas de colonização, contrariamente ao que se pretende, Enfantin, e também os são-simonianos, nunca foi verdadeiramente hostil à sua dimensão militar. Como podia sê-lo já que a colonização militar, como uma mo- 
toniveladora, limpava o terreno para a colonização econômica, ou melhor ainda, acompanhava-a? As críticas que ele endereça aos militares são organizacionais, sendo o essencial "a ordem segundo a qual essas duas espécies de colonização devem ser iniciadas e progressivamente desenvolvidas". As duas formas devem coexistir e influenciar-se reciprocamente, o triunfo da colonização é provável apenas se os civis forem militarizados, e não o contrário; isto é, os militares tornarem-se civis.

Essa colonização será de povoamento. É com ela que a idéia de povo europeu nascido da fusão sexual das nacionalidades ocidentais surgirá. Imbuído de uma visão organicista do mundo, Enfantin considera que "a cabeça" da colonização "deve ser francesa...".

Preocupado pela relação dos "indígenas" com a cidade, ele afirma que: "O islamismo nascido numa tribo nunca se mostrou muito hábil em fundar cidades", e ainda assinala: "As cidades da Argélia deviam encerrar uma população mole e covarde de escravos, ali alocada como um rebanho no estábulo".

A Argélia "não é o único país muçulmano onde existem poucas cidades; tribos nômades e fazendas isoladas, assim é a vida, em geral, nas sociedades muçulmanas." Apoiando-se nessa falsificação da história urbana árabe-muçulmana, ele conclui a seu respeito que "será então prudente não tentar impor-lhes demais nem rapidamente essa vida social das cidades".

Essa posição coincide com uma das orientações perenes da política colonial: um setor de atividade moderna, aquele do colonizador, formado por espaços de desenvolvimento e de prosperidade e, ao lado, a manutenção das estruturas tradicionais dos colonizados, amplamente anemizadas, no coração de uma sociedade "indígena" deixada em um estado perpétuo de subdesenvolvimento e movida por uma dinâmica da regressão nascida da destruição colonial dos antigos equilíbrios econômicos e sociais e da violentação cultural: em uma palavra, e para citar Enfantin, uma sociedade "determinada" por uma "rede de submissão".

\section{Para não concluir}

A participação dos são-simonianos na exploração e produção científica da Argélia foi central para o assentamento das redes de colonização. Nesse sentido, sua contribuição para a dominação e submissão da Argélia dá lugar muito facilmente a uma reputação de cientistas, de industriais ou de funcionários públicos altruístas, humanistas, construtores de redes, e guiados pelo espírito de "associação universal”.

Essa visão irênica confina com o mito. A esse respeito, a idéia de "rede de associação" deve ser seriamente questionada. Essa noção, em geral manejada como uma evidência, não funciona como uma relação de inversão e de dissimulação da realidade colonial? Seria possível pensar seriamente essa "associação" dissociando-a da "rede de submissão"? Associação e submissão não seriam essa dualidade, falsamente contraditória, do colonialismo? O são-simonismo, sejam quais forem suas tendências, em sua relação com a questão colonial, não se bene- 
ficiaria, no campo do conhecimento, de um tipo de impunidade epistemológica que lhe permite conservar através do tempo e do espaço, com custo mínimo, um tipo de pureza e de generosidade de intenção, ocultando assim suas dimensões racistas e negadoras dos Outros?

Finalmente, uma última interrogação: não poderia a herança intelectual e política de Saint-Simon ter alimentado, em nome de uma visão de mundo positivista, as teorias da exploração e da dominação colonial e, em conseqüência, as idéias e projetos colonialistas e neocolonialistas de seus herdeiros de ontem e de hoje? Existe aí, parece-nos, uma vasta exploração e produção científica, a ser ainda empreendida, sobre os escritos, as idéias e as vastas correntes de pensamento que se reivindicam herdeiras da filosofia das Luzes. Apenas um tal trabalho, desde que se apoiando em procedimentos resolutamente críticos, poderá contribuir para a revelação da face oculta de certos discursos que, travestindo-se de humanismo e fraternidade, encerram na verdade também um espírito de dominação e um sentimento de superioridade em relação ao Outro.

Notas

1 Este trabalho é a versão abreviada de um estudo apresentado no colóquio internacional "L'actualité du saint-simonisme", em Cerisy-la-Salle (França), julho de 2003. Por razões que seu autor ignora, o presente artigo foi eliminado das Atas do colóquio, publicadas pelas Presses Universitaires de France (2004) sob a direção do organizador do colóquio.

2 Em uma carta endereçada à Bugeaud em fevereiro de 1845, Enfantin, líder inconteste do são-simonismo, declara: "Quanto a mim, investi minha vida nisto...".

3 Projeto de lei UMP (Union pour un mouvement populaire) n.667, apresentado em 5 de maio de 2003, pelo deputado P. Douste-Blazy (atual ministro das Relações Exteriores). Votado pelo Parlamento francês, tornou-se "Lei de 20 de fevereiro de 2005", que exige que os professores do ensino secundário falem, em seus cursos, da obra de benfeitoria da França em suas ex-colônias.

4 Jean Pierre Chevènement, "Cessons d'avoir honte", Le Nouvel Observateur, 25.10. 2001.

5 As citações que seguem encontram-se, respectivamente, em: A.Picon, Industrie et régéneration sociale (p.10); Fondation Saint-Simon (1994); A. Pignol, "Les saintssimoniens et l'Orient" (p.188), in D'un Orient à l'autre (CNRS, 1991); M. Levallois, "Préface" (p.14 e 16), L’Algérie pour les algériens, de I. Urbain (Séguier, 2000, Paris).

6 Barthélemy Prosper Enfantin é considerado, juntamente com Armand Bazard, um dos herdeiros e continuadores do pensamento de Saint-Simon. No caso que nos interessa, ele foi um ator da colonização da Argélia.

7 A palavra "enfumaçamento" (em francês enfumade) designa uma prática das tropas militares francesas durante a conquista colonial; consistia em atear fogo e produzir grande quantidade de fumaça no interior das grutas em que se escondiam grupos de argelinos, fugindo, em busca de proteção, ao avanço dos invasores e de suas exações. 
Muitos dos integrantes de tais grupos, formados sobretudo por crianças, mulheres e idosos, morreram assim, asfixiados e queimados.

$8 \mathrm{Na}$ "mitologia colonial”, o "golpe enxota-moscas", dado pelo Dei de Argel ao cônsul francês que o havia desrespeitado, é o pretexto que justifica a invasão da Argélia pelas tropas francesas. Convocado pelo Dei que desejava obter explicações para o fato de a França não ter honrado suas dívidas junto à administração local, o cônsul respondeu de maneira injuriosa, o que motivou, por parte do Dei, um gesto brusco em sua direção, com o enxota-moscas. Os franceses teriam, portanto, invadido Argel para responder a essa afronta.

9 No Le National de 25 de agosto, E. Pereire propõe uma mesma tarifa aduaneira, um barco a vapor entre Marselha e Argel, uma via férrea ligando Oran, Argel, Bône.

10 Cf. o discurso ao parlamento de P. Leroux sobre "A organização do trabalho pela colonização".

11 A "Família" era o nome dado comumente pelos são-simonianos a seu grupo, cujo "pai supremo" era Enfantin.

12 Em francês, indigène, termo com o qual os colonizadores designavam um ser inferior. Essa conotação fortemente pejorativa do vocábulo explica por que ele foi escolhido, ironicamente, para dar nome a um movimento criado na França em 2005 por jovens franceses (de ambos os sexos) descendentes de imigrantes africanos e magrebinos: Les indigènes de la République.

13 Em Lettres d'un habitant de Genève, Saint-Simon considera que os acadêmicos estão a serviço do despotismo.

\section{Referências bibliográficas}

CARETTE, A.-M. (Capitaine). Étude sur la Kabilie (sic) proprement dite. s. 1. : Imprimerie Nationale, 1848.

DONDIN-PAYRE, M. La commission d'exploration scientifique d'Algérie. s. 1.: Institut de France. Imprimerie Paillard, 1995. p.22.

ENFANTIN, B.-P. La colonisation de l'Algérie. s. 1.: Imprimerie Bertrand, 1843.

LACHERAF, M. Les guerres coloniales en Algérie. Les Temps Modernes, janvier 1961.

SAÏD, E. L'orientalisme. Paris: Seuil, 1978. p.20.

RESUMO - POR TRÁs de seu projeto de "associação universal" com os povos colonizados ou em vias de sê-lo, o movimento são-simoniano é de fato obcecado pela implantação de "redes de submissão" em meio a esses povos, como de resto, de maneira mais ampla, também o são as elites francesas do século XIX, para além das clivagens ideológicas entre a esquerda e a direita.

PALAVRAS-CHAVE: Elites francesas e colonização, São-simonianos e associação universal, "Boa colonização e má colonização". 
ABSTRACT - BEHIND ITS project of an "universal association" with colonized people or people in the process of to become it, saint-simonien movement is obsessed by the establishment of "submission networks" within these people, as like as, widely, nineteenth's French elite, beyond ideological cleavages between the Left and the Right.

KEYWORDS: French elites and colonization, Saint-simoniens and universal association, "Good colonization and bad colonization".

Smaïl Hadj Ali é docente e pesquisador na Universidade de Rennes 2, depois de ter lecionado na Universidade de Argel. Como pesquisador, interessa-se há anos pelas dimensões culturais e intelectuais da política colonial francesa na Argélia. Atualmente desenvolve pesquisa sobre os usos das tecnologias da informação e da comunicação por populações socialmente desfavorecidas. É também membro de um grupo de pesquisas (dirigido por Armand Mattelart) sobre o papel das mídias européias na formação de um espaço público europeu no período que vai da assinatura do Tratado de Roma até os dias de hoje.

Tradução de René V. Lenard. O original em francês encontra-se à disposição do leitor no IEA-USP para eventual consulta.

Recebido em 10.12.2004 e aceito em 21.12.2004. 